\title{
Ensino médio integrado: subsunção aos interesses do capital ou travessia para a formação humana integral?
}

Dante Henrique Moura'

I- Instituto Federal de Educação, Ciência e Tecnologia do Rio Grande do Norte, Natal, RN, Brasil.

Contato: dante.moura@ifrn.edu.br

\section{Resumo}

Este artigo discute o significado do ensino médio na condição de etapa final da educação básica, tendo em vista a realidade socioeconômica e educacional brasileira, em que grande parte dos filhos das classes populares precisa trabalhar antes dos 18 anos de idade. Parte-se do pressuposto de que o objetivo a ser alcançado, na perspectiva de uma sociedade justa, é a formação omnilateral, integral ou politécnica de todos, de forma pública e igualitária e sob a responsabilidade do estado. Apesar de essa representar a utopia a ser buscada, a realidade atual está muito distante dessa perspectiva formativa. Neste trabalho, então, questiona-se: é possível caminhar nessa direção, mesmo em uma sociedade capitalista e periférica como a do Brasil? Tendo essa questão como norte do trabalho, discute-se o ensino médio integrado à educação profissional técnica de nível médio como uma possibilidade de travessia na direção formativa pretendida para os jovens brasileiros. 0 estudo foi desenvolvido tendo como referência os pensamentos de Karl Marx e Friedrich Engels, de Antonio Gramsci, assim como de autores que dialogam com eles. A análise permitiu concluir que a realidade socioeconômica brasileira exige, do ponto de vista teórico e ético-político, conceber e materializar um tipo de ensino médio que garanta uma base unitária para todos, fundamentado na concepção de formação humana integral, tendo como eixos estruturantes o trabalho, a ciência, a tecnologia e a cultura. Garantida essa mesma base, é preciso também que o ensino médio integrado à educação profissional técnica de nível médio seja colocado como uma possibilidade de formação.

\section{Palavras-chave}

Ensino médio integrado - Formação humana integral - Politecnia - Omnilateralidade. 


\title{
Integrated secondary education: subsumption to the interests of the capital or crossing towards an integral human formation?
}

Dante Henrique Moura'

\begin{abstract}
This article discusses the meaning of secondary education as the final stage in basic education, considering the Brazilian socioeconomic and educational reality, in which a large proportion of the children in the popular classes need to work before the age of 18. It assumes that the objective to be reached in the perspective of a fair society is the omnilateral, integral or polytechnic formation for all, in a public and egalitarian way, and under the responsibility of the state. Despite this representation of the utopia to be searched, the current reality is very far from such formative perspective. In this work, therefore, we question: is it possible to move in this direction, even in a capitalist and peripheral society such as Brazil? Having this question as a guideline, we discuss secondary education integrated to secondarylevel technical professional education as a possibility of changing towards the intended formation for Brazilian youngsters. The study was developed having as a reference the thought of Karl Marx and Friedrich Engels, and of Antonio Gramsci, as well as that of authors that dialogue with them. The analysis conducted made it possible to conclude that the Brazilian socio-economic reality requires, from a theoretical and ethical-political point of view, that we conceive and materialize a kind of secondary education that will guarantee $a$ unique basis for all, founded in the integral human formation, and having as its backbone the work, the science, the technology, and the culture. Once such basis is guaranteed, we also need that secondary education integrated into secondary-level technical professional education is offered as a possibility of formation.
\end{abstract}

\section{Keywords}

Integrated secondary education - Integral human formation Polytechnic - Omnilaterality.

I- Instituto Federal de Educação, Ciência e Tecnologia do Rio Grande do Norte, Natal, Brazil.

Contact:dante.moura@ifrn.edu.br 
Neste artigo, discute-se o significado do ensino médio na condição de etapa final da educação básica, tendo em vista a realidade socioeconômica e educacional brasileira, em que grande parte dos filhos das classes populares precisam trabalhar antes dos 18 anos de idade. Parte-se do pressuposto de que o objetivo a ser alcançado, na perspectiva de uma sociedade justa, é a formação omnilateral, integral ou politécnica de todos, de forma pública e igualitária e sob a responsabilidade do estado.

Apesar de essa representar a utopia a ser buscada, a realidade atual está distante anos luz dessa perspectiva formativa. Assim sendo, a questão fundamental que se coloca é: é possível dar passos nessa direção, mesmo em uma sociedade capitalista e periférica como a do nosso país?

Diante disso, o trabalho discute o ensino médio integrado à educação profissional técnica de nível médio, doravante EMI, como uma possibilidade de caminho a ser trilhado na direção pretendida. 0 estudo é desenvolvido a partir dos pensamentos de Marx, Engels, Gramsci e de autores que produzem ou produziram em diálogo com deles.

Compreende-se que tanto na formação omnilateral, politécnica ou integral, cuja gênese está na obra de Marx e Engels, como na escola unitária, de Gramsci, não há espaço para a profissionalização stricto sensu quando se trata da formação de adolescentes, tendo como referência a autonomia e a emancipação humana. Segundo o pensamento por eles defendido, formar, ainda na adolescência, o sujeito para uma determinada profıssão potencializa a unilateralidade em detrimento da omnilateralidade.

Apesar disso, tenta-se demonstrar que esses autores, ao discutirem a possibilidade de materialização da politecnia em seu sentido pleno - entendida como sinônimo de formação humana integral ou omnilateral e compatível com o conceito gramsciano de escola unitária -, referem-se a uma possibilidade futura a ser materializada em uma sociedade na qual a classe trabalhadora tenha conquistado o poder político.
Assim, quando discutem a educação do tempo em que viveram, ou seja, em uma sociedade capitalista, esses autores admitem a possibilidade da profissionalização quando associada à educação intelectual, física e tecnológica, compreendendo-a como o germe da educação do futuro (MARX, 1996).

Como o sistema capital e a burguesia continuam hegemônicos, se as hipóteses acima formuladas forem corretas, atualmente só é possível discutir a politecnia e a escola unitária em seus sentidos plenos e para todos em uma perspectiva de futuro. Nesse caso, o EMI pode ser considerado o germe da formação humana integral, omnilateral ou politécnica.

Feita essa breve aproximação ao problema em estudo, passa-se, na próxima seção, a discutir a profissionalização de adolescentes antes da conclusão da educação básica, tendo como referência os autores já mencionados. Em seguida, apresentam-se algumas considerações tendo em vista a continuidade do debate.

\section{Marx, Engels e Gramsci e a profissionalização}

Considerando a amplitude da obra e o fato de que os escritos de Karl Marx e Friedrich Engels, no campo pedagógico, não foram desenvolvidos isoladamente, mas em meio à análise da totalidade social, busca-se encontrar a proposição anunciada a partir da discussão de alguns textos nos quais tem relevância a formação humana, notadamente a da classe trabalhadora.

Para isso, seguir-se-á o caminho escolhido por Mario Manacorda. 0 autor afirma que:

Uma pesquisa filologicamente atenta às formulações explícitas de uma crítica e de uma perspectiva pedagógica nos textos de Marx - e nos de Engels, que são absolutamente inseparáveis - revela, sobretudo, a existência de textos explicitamente pedagógicos, que, sem serem numerosos, adquirem, no entanto, extraordinário relevo pela dupla 
circunstância de apresentarem, de novo e com coerência, no intervalo de mais de trinta anos, e de coincidirem com momentos cruciais tanto da sua investigação como da história do movimento operário. Isso ocorre precisamente por ocasião da redação de três programas políticos:

a. Para o primeiro movimento histórico da revolução, que assumiu o nome de Partido Comunista, às vésperas da revolução de 1848;

b. Para a I Associação Internacional dos Trabalhadores, em 1866;

c. Para o Primeiro Partido Operário Unitário, na Alemanha, em 1875. (MANACORDA, 2007, p. 34-35)

São quatro os textos aos quais se referem os itens $\mathrm{a}, \mathrm{b}$ e c acima mencionados e que servirão de guia à presente análise, no que se refere ao pensamento dos autores alemães. Os textos são, respectivamente: Manifesto do Partido Comunista (MARX; ENGELS, 1997); O capital (MARX, 1996); Instruções para os delegados do Conselho Central Provisório: as diferentes questões (MARX, 1982a); e $A$ critica ao programa de Gotha (MARX, 1982b). Compartilha-se com Manacorda a compreensão de que esses quatro textos são representativos do pensamento pedagógico dos mencionados autores, por isso serão revisitados na busca de confrontá-los com as hipóteses formuladas neste trabalho.

Em Manifesto do Partido Comunista, publicado originalmente em 1848, Marx e Engels (1997) afirmam que, após o primeiro passo da revolução operária - elevação do proletariado à condição de classe dominante - , faz-se necessário aplicar algumas medidas:

[...] que economicamente parecem insuficientes e insustentáveis mas que no decurso do movimento levam para além de si mesmas e são inevitáveis como meios de revolucionamento de todo o modo de produção. (MARX; ENGELS, 1997)
A décima medida, entre essas propostas por Marx e Engels é:

Educação pública e gratuita de todas as crianças. Eliminação do trabalho das crianças nas fábricas na sua forma hodierna. Unificação da educação com a produção material, etc.

A partir dessa citação, pode-se constatar claramente a perspectiva futura em relação às mudanças profundas a serem aplicadas à sociedade burguesa e que a transformarão em sociedade comunista. A lógica do Manifesto é, em primeiro lugar, a tomada do poder "a conquista da democracia pela luta” (MARX, 1982a), para em seguida aplicar medidas, inicialmente insuficientes, mas que gradualmente irão:

arrancar a pouco e pouco todo o capital à burguesia, para centralizar todos os instrumentos de produção na mão do Estado, i. é, do proletariado organizado como classe dominante. (MARX, 1982a)

Quando, dentre as medidas propostas, os autores tratam do campo educacional explicitam, dentre outros aspectos, a unificação da educação com a produção material. Portanto, Marx e Engels (1997) colocam essa possibilidade plena de unificação entre educação e produção material apenas em uma sociedade futura, após o domínio do poder político pela classe operária.

Evidentemente, isso não impede que, no transcurso da luta política da classe trabalhadora rumo ao domínio do poder político se produzam, dentro do conflito entre capital e trabalho, avanços quantitativos e qualitativos na perspectiva da superação da sociedade burguesa em geral e, em particular, de sua educação.

Em 1866, quase vinte anos após o Manifesto do Partido Comunista, Marx, em Instruções para os delegados do Conselho Central Provisório: as diferentes questões (1982b), formula um conjunto de teses para incorporação 
ao programa do partido como tarefas concretas a serem levadas a cabo, visando a fortalecer a luta rumo ao domínio do poder político. $\mathrm{Na}$ oportunidade, ele apresenta um texto mais elaborado a respeito da concepção educacional socialista, fundamentado na integração entre as dimensões intelectual, física e tecnológica, mas cuja gênese foi a unificação da educação com a produção material, anteriormente esboçada no Manifesto do Partido Comunista.

Praticamente no mesmo período, é publicado o primeiro volume de $O$ capital, de modo que Manacorda, ao se referir às Instruções para os delegados do Conselho Central Provisório: as diferentes questões, afırma que:

À leitura desse texto devemos imediatamente associar aquela de outro texto fundamental de Marx, O Capital. Seria aqui também bastante útil poder determinar com exatidão qual dos dois textos teria sido escrito antes, ou melhor, de que modo estão entrelaçados e sobrepostos (MANACORDA, 2007, p. 45).

Como se vê, os dois textos de Marx são imbricados, mas com características diferentes, pois destinam-se a distintos fins. Enquanto Instruções para os delegados do Conselho Central Provisório: as diferentes questões constituem uma proposta de programa do partido e, portanto, tem uma linguagem mais direta e sucinta, 0 capital, considerada por muitos a obra principal do autor, apresenta análises completas e aprofundadas de Marx, decorrentes de suas pesquisas no campo da crítica à economia política.

Então, de forma coerente com o que está na tese a respeito do ensino, sustentada no texto de 1866, Marx, no capítulo XIII de $O$ capital, ao se referir à legislação fabril inglesa, esclarece que na luta pela conquista do poder há fases intermediárias que vão se engendrando na medida em que as posições relativas das classes em conflito se alteram de acordo com a correlação de forças entre elas.
No caso específico, o autor coloca "como primeira concessão penosamente arrancada ao capital” (MARX, 1996, p. 116), a conjugação de ensino elementar com o trabalho fabril seguramente profissionalizante - que, apesar de ainda estar longe da politecnia, traz o seu germe. Ele conclui o raciocínio afirmando que:

[...] não há dúvida de que a inevitável conquista do poder político pela classe operária há de conquistar também para o ensino teórico e prático da tecnologia seu lugar nas escolas dos trabalhadores. (MARX, 1996, p. 116).

Conclui-se, da análise conjunta das duas obras, que, igualmente ao proposto no Manifesto do Partido Comunista, a perspectiva da politecnia em seu sentido pleno está colocada apenas para uma sociedade na qual a classe trabalhadora tenha o domínio do poder político, mas que é possível ir avançando nessa direção, ainda na sociedade burguesa, aproveitando-se das contradições do modo de produção capitalista.

Examinar-se-á agora a obra Crítica ao programa de Gotha (1982b). Esse texto, prefaciado por Engels, foi escrito cerca de dez anos após as Instruções para os delegados do Conselho Central Provisório: as diferentes questões e $O$ Capital e quase trinta após o Manifesto do Partido Comunista. Constituise em uma dura e polêmica crítica de Marx ao que seria o Programa do Partido Operário Socialista da Alemanha, partido esse que foi fruto da unificação, que ocorreu durante o Congresso de Gotha, em maio de 1875, entre o Partido Operário Social-Democrata e a União Geral Operária Alemã. No tocante à educação, o Programa propõe, segundo Marx:

0 Partido Operário Alemão reclama como base espiritual e ética [sittlich] do Estado: 1. Educação popular geral e igual pelo Estado. Escolaridade obrigatória geral. Instrução gratuita. (MARX, 1982b) 
Nesse texto, a análise da crítica de Marx a essa proposta será restrita ao primeiro item, uma vez que o autor exclui a discussão acerca do estado, pois já julga esse primeiro ponto como suficiente para argumentar a favor da proposição que vem tentando sustentar. Nesse sentido, Marx, ao analisar a proposição do Partido Operário Alemão, vaticina:

Educação popular igual? 0 que é que se imagina por detrás destas palavras? Acredita-se que na sociedade hodierna (e é só com ela que se tem que ver) a educação pode ser igual para todas as classes? Ou reclama-se que as classes superiores também devem ser reduzidas compulsivamente ao módico da educação - da escola primária [Volksschule] - o único compatível com as condições económicas, não só dos operários assalariados, mas também dos camponeses? (MARX, 1982, grifos do autor)

Evidentemente, a compreensão do conjunto da obra de Marx e Engels evidencia que a crítica a essa proposição do programa de Gotha está na impossibilidade de sua materialização na sociedade da época em que os textos foram escritos. Dessa forma, critica-se o fato de que ao invés de apresentar-se uma tese dialeticamente factível, essa se constituiu em uma declaração de intenções, sem possibilidade de materialização, posto que é descolada da realidade concreta.

É por isso que Marx (1982a), ao continuar sua Crítica ao programa de Gotha, afırma "0 parágrafo sobre as escolas deveria, pelo menos, ter reclamado escolas técnicas (teóricas e práticas) em ligação com a escola primária." Corrobora-se, portanto, com Manacorda quando, ao se referir a esse texto, explica a decidida recusa de Marx:

[...] de uma educação igual para todas as classes, pelo menos como objetivo a ser imediatamente realizado na sociedade atual, burguesa, [...] o ensino não pode ser de repente transmitido igual a todas as classes, sem o risco, evidentemente, de um rebaixamento de nível, como hoje se diz. [...] No entanto, justamente [...] em 'na sociedade atual [hodierna]', reafirma-se indiretamente que, na sociedade do futuro, será diferente: não é à toa que o vínculo ensino-trabalho (que, segundo as Instruções de 1866, por compreender também a formação intelectual, era tal que permitiria elevar a classe operária muito acima das classes superiores e médias) aparece aqui formulado como um dos mais potentes meios de transformação da sociedade atual. (MANACORDA, 2007, p. 54)

Como se vê, em Crítica ao programa de Gotha, Marx e Engels reafirmam que a politecnia plena e para todos só seria possível após a conquista do poder político da sociedade pela classe trabalhadora.

Tendo examinado o tema da educação em Marx e Engels, passa-se, nesse momento, a buscar no pensamento de Antonio Gramsci evidências de que sua negação a qualquer possibilidade de profıssionalização na etapa final da educação básica também está colocada em uma perspectiva futura, portanto, em uma sociedade em que o poder político já estivesse sob o domínio da classe trabalhadora e, dessa forma, diferente da sociedade italiana na qual e partir da qual produziu, mormente, a sua obra.

As concepções de Gramsci a respeito da escola unitária e de formação humana integral, omnilateral ou politécnica, provenientes de Marx e de Engels, não colidem. Ao contrário, compreende-se que são complementares, tendo quem vista que Gramsci aprofunda um aspecto da politecnia anunciado, mas não muito explorado pelos autores alemães, qual seja: a dimensão intelectual, cultural e humanística.

Nesse sentido, Manacorda (2007, p. 137), ao tecer um diálogo entre esses três autores, afirma que:

É comum a tendência de enfatizar, em Gramsci, o momento cultural, humanístico; 
e nada haveria a objetar a essa tendência, já que, ao lado das precisas proposições da proposta marxiana quanto ao nexo entre ensino e trabalho, existe, em Gramsci, uma ênfase consciente quanto à exigência cultural, que, no contexto supracitado, ele define como humanística e formativa. Mas, assim como seria errado entender esse humanismo no sentido tradicional, também, e até mais, seria errado assinalar, nesses elementos culturais, a sua separação de Marx (um Marx praticista em confronto com um Gramsci humanista), esquecendose, em suma, de que esses elementos estão bem presentes também em Marx, que, de maneira não-casual, fala em formação intelectual ou espiritual (geistig) e, como já vimos, sabe bem apreciar toda a riqueza da vida espiritual do homem.

Concordando com Manacorda, concluise que a escola unitária vai ao encontro da formação humana integral e é o lugar onde ela deverá ocorrer. Recorrendo diretamente a Gramsci (1982, p. 121), em sua formulação a respeito da escola unitária, ele defende que:

A escola unitária ou de formação humanista (entendido este termo, 'humanismo', em sentido amplo e não apenas em sentido tradicional) ou de cultura geral deveria se propor a tarefa de inserir os jovens na atividade social, depois de tê-los levado a um certo grau de maturidade e capacidade, à criação intelectual e prática e a uma certa autonomia na orientação e na iniciativa.

Aqui se encontra claramente o vínculo entre a escola unitária e a formação politécnica. Mas, em primeiro lugar, é importante esclarecer a compreensão de Gramsci acerca da formação humanista. Para o autor, o humanismo não pode ser compreendido em sua forma tradicional, liberal, voltado para o ensino memorístico, mas se trata de um humanismo que contribua para o desenvolvimento, nos sujeitos, da capacidade de criação intelectual e prática, além de servir para a compreensão da totalidade social, tendo o trabalho como princípio educativo como sua base.

Para Gramsci, nessa escola não há espaço para a profissionalização. Assim, o autor critica a tendência italiana de:

[...] abolir qualquer tipo de escola 'desinteressada' (não imediatamente interessada) e 'formativa', [...] bem como a de difundir cada vez mais as escolas profissionais especializadas, nas quais o destino do aluno e sua futura atividade são predeterminados. (GRAMSCI, 1982, p. 118)

Especificamente a respeito da última etapa da escola unitária, equivalente ao atual ensino médio brasileiro, ele propõe que:

[...] na escola unitária, a última fase deve ser concebida e organizada como a fase decisiva, na qual se tende a criar os valores fundamentais do "humanismo", a auto-disciplina intelectual e a autonomia moral necessárias a uma posterior especialização, seja ela de caráter científico (estudos universitários), seja de caráter imediatamente prático-produtivo (indústria, burocracia, organização das trocas, etc.). 0 estudo e o aprendizado dos métodos criativos na ciência e na vida deve começar nesta última fase da escola, e não deve ser mais um monopólio da universidade ou ser deixado ao acaso da vida prática: esta fase escolar já deve contribuir para desenvolver o elemento da responsabilidade autônoma nos indivíduos, deve ser uma escola criadora. (GRAMSCI, 1982, p.65)

Dessa forma, o autor é explícito em sua posição acerca da profissionalização. Para ele, seja em caráter universitário ou não, a formação profissional deverá ser posterior à escola unitária humanista, de cultura geral e fundamentada no princípio educativo do trabalho. 
Não obstante, tal qual Marx e Engels se referem à politecnia em seu sentido pleno como uma perspectiva educacional futura, Gramsci também considera a escola unitária dessa forma. Isso porque, segundo o autor, as condições materiais concretas da sociedade de sua época impediam a plena materialização da politecnia. Cabe ressaltar que essa situação permanece no Brasil de hoje. Gramsci aceita, assim, que a realidade concreta impunha a profissionalização de parte dos adolescentes e jovens antes da conclusão da última etapa da educação básica.

Encontram-se evidências dessa concessão do autor diretamente em sua obra. Ao referir-se à idade escolar, Gramsci (1982, p.121) reconhece que:

A fixação da idade escolar obrigatória depende das condições econômicas gerais, já que estas podem obrigar os jovens a uma certa colaboração produtiva imediata.

Nesse trecho, ao afirmar que no tempo presente as "condições econômicas gerais" podem exigir que jovens tenham de trabalhar antes de concluir a escola unitária, ele não admite diretamente a profissionalização, mas reconhece a necessidade da existência de escolas distintas em uma fase de transição, o que remete à possibilidade de profissionalização precoce dos jovens cujas condições de vida assim o exijam.

0 autor continua sua análise alinhando fatos que impõem limites à escola unitária, ao menos, inicialmente. Reconhece que muitas mudanças imprescindíveis à sua materialização implicam decisão política e grande ampliação do orçamento destinado à educação. Esclarece isso, mencionando que:

A escola unitária requer que o Estado possa assumir as despesas que hoje estão a cargo da família, no que toca à manutenção dos escolares, isto é, que seja completamente transformado o orçamento da educação nacional, ampliando-o de um modo imprevisto e tornando-o mais complexo: a inteira função de educação e formação das novas gerações torna-se, ao invés de privada, pública, pois somente assim pode ela envolver todas as gerações, sem divisões de grupos ou castas. Mas esta transformação da atividade escolar requer uma ampliação imprevista da organização prática da escola, isto é, dos prédios, do material científico, do corpo docente etc. 0 corpo docente, particularmente, deveria ser aumentado, pois a eficiência da escola é muito maior e intensa quando a relação entre professor e aluno é menor, o que coloca outros problemas de solução difícil e demorada. Também a questão dos prédios não é simples, pois este tipo de escola deveria ser uma escola-colégio, com dormitórios, refeitórios, bibliotecas especializadas, salas aptas ao trabalho de seminário etc. (GRAMSCI, 1982, p.121-122)

0 autor conclui sua argumentação explicando que:

Por isso, inicialmente, o novo tipo de escola deverá ser - e não poderá deixar de sêlo - própria de grupos restritos, de jovens escolhidos por concurso ou indicados, sob sua responsabilidade, por instituições idôneas”. (GRAMSCI, 1982, p. 122)

De sua conclusão depreende-se que a mudança para a escola unitária para todos não ocorrerá sem uma fase de transição. Ao contrário, tal fase é inevitável e durante esse período coexistirão distintas escolas, dentre elas as técnicas. Gramsci (1982, p. 122) não faz essa afırmação diretamente, mas ao dizer que na Itália havia a tendência "de difundir cada vez mais as escolas profissionais especializadas" e que o novo tipo de escola, inicialmente, não seria para todos, fica evidente que ele tinha plena consciência da continuidade dessas escolas técnicas por algum período, cuja duração era impossivel de ser prevista com precisão. 
Após revisitar a questão educacional em Marx e Engels e em Gramsci, compreendese que as hipóteses de partida aqui propostas são válidas. Nesse sentido, defende-se que a concepção educacional desses autores está pensada tendo como lócus para a sua materialização a sociedade futura (socialista) e que, dessa forma, atualmente ainda não se pode concretizar a politecnia e a escola unitária em seus sentidos plenos para todos.

Isso só será possível em uma perspectiva de futuro. Não obstante, também se conclui, a partir do pensamento desses autores, que é possível, e necessário, plantar e cuidar para que cresçam as sementes da formação humana integral, aproveitando-se das contradições do sistema capital.

Para tanto, no caminho para a travessia em direção à escola unitária, laica, politécnica, universal, pública e gratuita é necessário reclamar por escolas técnicas (teóricas e práticas), nas quais está o germe do ensino que poderá elevar a educação da classe operária bastante acima do nível das classes superior e média (MARX, 1996). Se essa tese é válida para a classe trabalhadora em geral, para o caso do Brasil, imerso no capitalismo neoliberal como quase todo o planeta e, além disso, estando na periferia desse sistema capital, ela tem mais potência ainda.

Em nosso país, a situação da classe trabalhadora é muito mais degradante do que nas regiões de capitalismo avançado, as quais de uma ou outra maneira passaram pelo estado de bem-estar social, o que garantiu aos trabalhadores alguns direitos sociais básicos e a manutenção deles, mesmo considerando a crise que atravessam atualmente. Desde logo, isso não aconteceu na zona periférica do capitalismo, em que está inserido o Brasil.

A extrema desigualdade socioeconômica obriga grande parte dos filhos da classe trabalhadora nacional a buscar, muito antes dos 18 anos de idade (e até crianças), a inserção no mundo do trabalho, no intuito de complementar a renda familiar ou até de autossustentação. Essas pessoas seguem, com baixíssima escolaridade e sem nenhuma qualificação profissional, engordando as fileiras do trabalho simples, mas contribuindo fortemente para a valorização do capital. É a nossa realidade rebelde (SAVIANI, 2003a).

Ao retornar a Marx e Engels, principalmente na Crítica ao programa de Gotha, e pensando dialeticamente no movimento do real na sociedade brasileira atual (e só dela podemos falar - parafraseando Marx) é inevitável perguntar: diante da realidade concreta pode-se hoje, no Brasil, pensar na educação escolar dos adolescentes e jovens da classe trabalhadora negando qualquer possibilidade de que eles tenham que trabalhar antes dos 18 anos de idade?

Alguns indicadores sociais da população de até 17 anos de idade resultantes da Pesquisa Nacional por Amostra de Domicílios (PNAD), feita pelo Instituto Brasileiro de Geografia e Estatística (IBGE) em 2008, apresentados nas tabelas 1, 2, 3 e 4, ajudam a responder a esse questionamento.

Tabela 1 - Crianças e adolescentes de 10 a 17 anos de idade, por grupos de idade, total e respectiva distribuição percentual, por condição de atividade na semana de referência, Brasil - 2007

Crianças e adolescentes de 10 a 17 anos de idade, por grupos de idade

\begin{tabular}{|c|c|c|c|c|c|c|c|c|c|c|c|}
\hline \multirow{3}{*}{ Brasil } & \multirow{3}{*}{$\begin{array}{c}\text { Total } \\
\text { (milhões de } \\
\text { pessoas) }\end{array}$} & \multicolumn{10}{|c|}{ Distribuição percentual, por condição de atividade na semana de referência (pessoas e \%) } \\
\hline & & \multicolumn{2}{|c|}{ Só estuda } & \multicolumn{2}{|c|}{ Trabalha e estuda } & \multicolumn{2}{|c|}{ Só trabalha } & \multicolumn{2}{|c|}{$\begin{array}{c}\text { Cuida de afazeres } \\
\text { domésticos }\end{array}$} & \multicolumn{2}{|c|}{$\begin{array}{c}\text { Não realiza nenhuma } \\
\text { atividade }\end{array}$} \\
\hline & & Pessoas & $\%$ & Pessoas & $\%$ & Pessoas & $\%$ & Pessoas & $\%$ & Pessoas & $\%$ \\
\hline 10 a 15 anos & 21,334 & 18.581 .914 & 87,1 & 1.920 .060 & 9,0 & 234.674 & 1,1 & 362.678 & 1,7 & 256.008 & 1,2 \\
\hline 16 e 17 anos & 6,777 & 3.713 .796 & 54,8 & 1.585 .818 & 23,4 & 691.254 & 10,2 & 562.491 & 8,3 & 223.641 & 3,3 \\
\hline 10 a 17 anos & 28,111 & 22.295.710 & 79,31 & 3.505 .878 & 12,47 & 925.928 & 3,29 & 925.169 & 3,29 & 479.649 & 1,71 \\
\hline
\end{tabular}

Fonte: Elaboração própria, a partir da tabela 6.7/Indicadores Socais da PNAD 2008. 
Tabela 2 - Crianças e adolescentes de 10 a 17 anos de idade, ocupados na semana de referência, total e respectiva distribuição percentual, por grupos de idade em que começaram a trabalhar, segundo Brasil - 2007

\begin{tabular}{|c|c|c|c|}
\hline \multicolumn{4}{|c|}{ Crianças e adolescentes de 10 a 17 anos de idade, ocupados na semana de referência } \\
\hline \multirow{2}{*}{ Total (1.000 pessoas) } & \multicolumn{3}{|c|}{ Distribuição percentual, por grupos de idade em que começaram a trabalhar (\%) } \\
\hline & Até 9 anos & 10 a 15 anos & 16 a 17 anos \\
\hline 4.668 & 19,1 & 66,1 & 14,8 \\
\hline
\end{tabular}

Fonte: Adaptação da tabela 6.16/Indicadores Sociais da PNAD 2008.

Ao analisar a tabela 1, considerando que quem cuida de afazeres domésticos está trabalhando, evidencia-se que 41,9\% dos adolescentes da faixa etária dos 16 aos 17 anos de idade residentes no Brasil trabalham. Se se levasse em consideração que os 3,3\% dessa faixa etária que não realiza nenhuma atividade (nem trabalha nem estuda) estão muito mais próximos do trabalho do que da escola, chegase ao percentual de 45,2\% dos jovens entre 16 e 17 anos de idade como sendo trabalhadores, empregados ou não.

Além disso, não é insignificante a quantidade de crianças que trabalham, pois são 2.517.412
$(11,8 \%)$ da faixa etária dos 10 aos 15 anos de idade nessa condição, cabendo destacar que no Brasil é legalmente proibido trabalhar antes dos 14 anos de idade, ou seja, nessa faixa etária apenas os que estão entre 14 e 15 anos poderiam trabalhar legalmente, na condição de aprendizes.

Ainda mais, dos jovens que trabalham entre os 10 e os 17 anos de idade, 19,1\% deles começaram a vida laboral até os nove anos de idade, conforme evidenciado na tabela 2. Cabe, neste momento, a indagação: por que trabalham esses adolescentes e crianças? As tabelas 3 e 4 dão informações que ajudam a responder a essa pergunta.

Tabela 3 - Pessoas de 0 a 17 anos de idade residentes em domicílios particulares, total e respectiva distribuição percentual, por classes de rendimento mensal familiar per capita, segundo Brasil - 2007

\begin{tabular}{|c|c|c|c|c|c|c|}
\hline \multicolumn{7}{|c|}{ Pessoas de 0 a 17 anos de idade residentes em domicílios particulares } \\
\hline \multicolumn{7}{|c|}{ Total } \\
\hline \multicolumn{7}{|c|}{ Distribuição percentual, por classes de rendimento mensal familiar per capita (salário mínimo) (\%) } \\
\hline Até $1 / 4$ & $\begin{array}{c}\text { Mais de } \\
1 / 4 \text { a } 1 / 2\end{array}$ & $\begin{array}{l}\text { Mais de } \\
1 / 2 \text { a } 1 \\
\end{array}$ & $\begin{array}{c}\text { Mais de } \\
1 \mathrm{a} 2 \\
\end{array}$ & $\begin{array}{c}\text { Mais de } \\
2 \text { a } 3 \\
\end{array}$ & $\begin{array}{c}\text { Mais de } \\
3 \text { a } 5 \\
\end{array}$ & $\begin{array}{c}\text { Mais de } \\
5 \\
\end{array}$ \\
\hline 19,6 & 26,1 & 26,3 & 14,6 & 3,9 & 2,7 & 1,7 \\
\hline
\end{tabular}

Fonte: Adaptação da tabela 6.20/Indicadores Sociais da PNAD 2008.

Tabela 4 - Distribuição percentual das crianças e adolescentes de 5 a 15 anos de idade, ocupados na semana de referência, por classes de contribuição no rendimento médio mensal familiar, segundo Brasil - 2007

\begin{tabular}{ccccc}
\hline $\begin{array}{c}\text { Distribuição percentual das crianças e adolescentes de } \mathbf{5} \text { a } 15 \text { anos de idade, ocupados na semana de referência, por } \\
\text { classes de contribuição no rendimento médio mensal familiar (\%) }\end{array}$ \\
\hline Até 10\% & $\vdots$ & Mais de 10\% a 30\% & $\vdots$ & Mais de $30 \%$ \\
\hline 41,5 & $\vdots$ & 43,2 & $\vdots$ & 15,4 \\
\hline
\end{tabular}

Fonte: Adaptação da Tabela 6.17/Indicadores Sociais da PNAD 2008. 
A tabela 3 informa que a maioria das pessoas entre 10 e 17 anos estão inseridas em famílias pobres ou muito pobres, pois dos 58,5 milhões dessa faixa etária, que moram em domicílios particulares, 77,1\% residem em habitações cuja renda per capita mensal é de, no máximo, um salário mínimo. Caso esse limite seja aumentado para dois salários mínimos, o percentual sobe para 91,7\%.

É precisamente por isso que a atividade remunerada dessas crianças, adolescentes e jovens é significativa para a sobrevivência do núcleo familiar, tal como revela a tabela 4 . Nela está explícito que 58,6\% das crianças e adolescentes de 5 a 15 anos de idade contribuem com mais de $10 \%$ do rendimento familiar, sendo que 15,4\% são responsáveis por mais de 30\% do orçamento dos residentes no domicílio.

Ressalte-se, nesse caso, que a gravidade é maior, pois o IBGE/PNAD não disponibilizou os dados para a faixa etária dos 10 aos 17, mas dos 5 aos 15 anos de idade. Isso evidencia que sequer se está falando da luta de Marx e Engels para regulamentar o trabalho infantil a partir dos 9 anos de idade na Inglaterra do início da revolução industrial. Aqui se trata de discutir o trabalho a partir dos 5 anos de idade.

Diante desse panorama, no caso das pessoas de até 17 anos de idade, de que adianta(ria) pensar em um sistema educacional voltado exclusivamente para os que não trabalham, se a realidade se impõe em direção diametralmente oposta como acaba de ser evidenciado com dados oficiais que, inclusive, costumam ser mais generosos do que a realidade em si?

Nesse caso, cabe outro questionamento: pensar de forma coerente com o materialismo histórico dialético não é compreender essa realidade socioeconômica e tentar arrancar do capital concessões que contribuam para a formação integral da classe trabalhadora, mesmo que, inicialmente, não seja na plenitude do conceito de politecnia para todos, mas que se garanta para todos a indissociabilidade entre formação intelectual, física e tecnológica, sem, com isso, abandonar a denúncia e o combate a todas as atrocidades cometidas contra essas crianças, adolescentes e jovens? Não foi isso o que fizeram Marx e Engels em relação ao trabalho infantil na Inglaterra do século XIX?

A análise até aqui desenvolvida permite concluir que a realidade socioeconômica brasileira exige, do ponto de vista teórico e ético-político, conceber e materializar um tipo de ensino médio que garanta uma base unitária para todos, fundamentado na concepção de formação humana integral, omnilateral ou politécnica, tendo como eixo estruturante o trabalho, a ciência, a tecnologia e a cultura. Além disso, garantida essa mesma base, exige também proporcionar o EMI como uma opção.

Nessa perspectiva, concorda-se com Frigotto, Ciavatta e Ramos (2005a), quando problematizam a profissionalização no ensino médio brasileiro. Para eles,

Se a preparação profissional no ensino médio é uma imposição da realidade, admitir legalmente essa necessidade é um problema ético. Não obstante, se o que se persegue não é somente atender a essa necessidade mas mudar as condições em que ela se constitui, é também uma obrigação ética e política, garantir que o ensino médio se desenvolva sobre uma base unitária para todos. Portanto, o ensino médio integrado ao ensino técnico, sob uma base unitária de formação geral, é uma condição necessária para se fazer a "travessia" para uma nova realidade. (FRIGOTTO; CIAVATTA; RAMOS, 2005a, p.43)

Evidentemente, essa travessia para uma nova realidade, à qual se referem os autores, é a construção de uma sociedade futura, tantas vezes mencionada por Marx e Engels, e já discutida ao longo deste texto.

Nessa travessia, as duas formas de organizar o ensino médio - ensino médio politécnico e ensino médio politécnico integrado à educação profissional - são coerentes e poderão coexistir até que as condições materiais 
objetivas da sociedade brasileira sejam tais que permitam aos jovens das classes populares concluírem a educação básica por volta dos 17 ou 18 anos de idade e somente então pensarem em uma profissionalização. Hoje isso é um luxo para os filhos da classe trabalhadora, embora há muito tempo já seja garantido como direito - exclusivo - dos jovens dos estratos médios e altos da população.

Para que esse luxo seja extensivo às classes populares, a maioria dos milhões de jovens que estudam nas redes públicas de ensino estaduais e municipais, será necessário um período de tempo impossivel de se prever nesse momento.

Na mesma linha do que mencionou Gramsci ao se referir à materialização da escola unitária na realidade italiana da primeira metade do século XX, movimentos nessa direção só ocorrerão a partir de uma grande pressão da sociedade organizada sobre o estado, visando ao desenvolvimento de ações planejadas que contemplem, além da concepção e dos princípios norteadores desse ensino médio, dimensões como financiamento, colaboração entre os entes federados e as redes públicas, quadro de profissionais da educação e sua adequada formação inicial e continuada e infraestrutura física, prédios, bibliotecas, laboratórios, instalações desportivas etc. Ou seja, a partir de um projeto societário e, em consequência, educacional, diferente do hegemônico da atualidade, no marco da luta pela superação da sociedade burguesa (MOURA, 2012, p. 53).

Some-se ao exposto até aqui o fato de que, para além dos adolescentes e jovens, existe a população adulta brasileira, predominantemente com baixa escolarização. Maria Margarida Machado (2010) desenvolveu um importante estudo a respeito da escolarização das pessoas adultas, cujos dados apontam que no Brasil existem quase 135 milhões de pessoas com 18 anos ou mais, das quais cerca de 101 milhões, 75\% da faixa etária, não concluiu a educação básica.
Buscando identificar a parcela desses sujeitos de direito que poderia demandar por escolarização, a autora, a partir dos dados acima, conclui:

Em se projetando uma oferta de educação
diferenciada, por exemplo, aos idosos de
60 anos e mais, que necessariamente não
se comparasse à educação básica, ainda
assim a população de 18 a 59 anos, que
representa um total de 79.511 .036 de
pessoas, é demanda potencial para a
educação básica. Todos esses números
enfatizam mais uma vez que não se trata,
na realidade brasileira, de considerar
a demanda por educação de jovens e
adultos como residual. (MACHADO, 2010,
p. 252-253)

0 estudo da professora Margarida Machado reforça de maneira significativa toda a argumentação até aqui desenvolvida, uma vez que a fase adulta é aquela em que o ser humano é essencialmente um sujeito de trabalho, pois é responsável pela produção da própria existência e da sociedade, além de lhe caber a reprodução da espécie.

Desafortunadamente, no caso brasileiro, a grande maioria desses quase 80 milhões de pessoas com mais de 18 anos está atuando na periferia do mundo do trabalho de forma precarizada ou dele alijada. A dura realidade obriga a lembrar que isso é funcional aos interesses do capital, pois, já que não há lugar para todos, que vençam os melhores!

\section{Considerações à continuidade do debate}

Diante da análise empreendida, reitera-se a compreensão de que é um imperativo ético-político a constituição do EMI a partir de uma base unitária de formação, na perspectiva da omnilateralidade. Apesar disso, como não se pode esquecer em nenhum momento de que a realidade concreta se impõe, importa evidenciar 
que a materialização dessa concepção educacional enfrenta dificuldades de múltiplas ordens.

A primeira é a disputa política direta com o capital, uma vez que esse tipo de formação claramente não lhe interessa. Dessa forma, seus representantes e intelectuais orgânicos, que no campo da formação profissional são capitaneados pelo sistema S, defendem ardorosamente, embora com desfaçatez, a formação estrita para o atendimento imediato aos interesses do mercado de trabalho.

Enquanto isso, o governo federal tem posição completamente ambígua, raiando a esquizofrenia. Às vezes adota o discurso da politecnia e da formação humana integral, mas, nesse caso, vai muito pouco além das palavras. Outras vezes assume, em nome dos interesses dos trabalhadores e dos mais pobres, o que, na verdade, interessa ao capital. Nesse caso, vai além das palavras e promove ações efetivas, inclusive, financiando-as regiamente.

o Programa Nacional de Acesso ao Ensino Técnico e Emprego (PRONATEC) é um exemplo emblemático na atualidade. Esse Programa destina-se a oferecer, entre 2011 e 2014, cerca de 7,9 milhões de matrículas, sendo 5,6 milhões em cursos de Formação Inicial e Continuada de trabalhadores (FIC), sem vinculação com a elevação de escolaridade, e 2,3 milhões em cursos técnicos concomitantes ao ensino médio para estudantes das redes públicas estaduais (BRASIL, 2012).

Trata-se de cursos fora da perspectiva da formação humana integral prevista no EMI. A esse Programa estão sendo destinados R $\$ 24$ bilhões e os cursos são/serão oferecidos em sua maioria pelo sistema $S$, mediante transferência da maior parte desses recursos públicos provenientes do governo federal.

Nas esferas subnacionais a situação é ainda mais complexa, pois na ausência efetiva de um sistema nacional de educação, de uma concepção educacional que lhe oriente e de coordenação das ações em nível nacional, os estados e os municípios, a cada ciclo de governo, a exemplo da esfera federal, apontam para uma determinada direção.
Entretanto, observa-se que o metabolismo do capital faz com que, em geral, o movimento da educação proporcionada à classe trabalhadora tenha certa coerência interna entre as três esferas de governo, de modo que o pêndulo pende para o tipo de formação que interessa às necessidades imediatas do capital.

Além disso, a sociedade em geral, principalmente grandes contingentes das classes trabalhadoras populares não organizadas - historicamente alijadas do acesso a uma educação de qualidade socialmente referenciada e a outros direitos sociais que, em seu conjunto, viabilizaria uma compreensão crítica da realidade vigente -, está sempre ávida por qualquer migalha que lhe seja atirada e, dessa forma, tende a aplaudir, agradecer e reivindicar por mais algumas dessas migalhas ${ }^{1}$.

Finalmente, o EMI enfrenta a crítica no âmbito da academia, desde as correntes mais conservadoras, que defendem a educação de cunho academicista, inspirada no iluminismo, no humanismo liberal, até os progressistas que o consideram como uma concessão aos interesses do capital.

Nesse contexto, ao se deixar (a academia, outros intelectuais, a maioria da classe trabalhadora e de suas entidades representativas) de disputar politicamente uma concepção de EMI (para adolescentes, jovens e adultos) que possa se concretizar como ponte na direção da formação politécnica plena (SAVIANI, 2003b; RAMOS, 2004; FRIGOTTO; CIAVATTA; RAMOS, 2005b; FRIGOTTO; CIAVATTA, 2006; KUENZER, 1997, 2006, 2010, 2011; MACHADO, 2008, 2009) se está abrindo espaço e estendendo o tapete vermelho para que o capital se aproprie de bandeiras históricas do campo socialista e as ressignifique alegremente em favor dos seus interesses, com financiamento público e aplausos da população.

1- Há exceções, com destaque para o Movimento dos Sem Terra (MST) cuja luta por outra sociedade é emblemática. 0 MST desenvolve ações que são referência quando se trata de construir um projeto educacional integrado a um projeto social contra-hegemônico voltado aos interesses da classe trabalhadora. 
Como então é possível superar essas barreiras e avançar na construção teóricoprática dessa perspectiva formativa? Reitera-se que o principal óbice é de natureza política, pois falta a decisão política de o estado ${ }^{2}$ brasileiro assumir a omnilateralidade como sendo a concepção norteadora da formação de todos, independentemente da origem socioeconômica, e, partir dessa referência, iniciar a travessia.

Infelizmente, a falta dessa decisão é coerente com o modelo de sociedade em que se vive, pautada pelo pensamento neoliberal que considera a desigualdade social como elemento indispensável ao fortalecimento dos mercados, já que é ela que potencializa a competitividade, alimento vital do mercado. Compreende-se, portanto, que o caminho para a travessia só poderá ser construído a partir de disputas políticas em meio às contradições do sistema capital.

Alguns movimentos recentes no âmbito do ensino médio e da educação profissional são esclarecedores dessas disputas e contradições. Por um lado, as novas Diretrizes Curriculares Nacionais para a Educação Profissional Técnica de Nível Médio (DCNEPTNM) reiteram uma concepção de formação humana instrumental e utilitária, podendo ser sintetizada nas seguintes características: centralidade nas competências; submissão explícita da escola e da formação humana à lógica do mercado de trabalho; ênfase nas certificações parciais, ensejando a volta da modularização e das saídas intermediárias; priorização das formas subsequente e concomitante ao ensino médio em detrimento do $\mathrm{EMI}^{3}$.

Por outro lado, as novas Diretrizes Curriculares Nacionais para o Ensino Médio (DCNEM) apontam claramente para a perspectiva da formação humana integral, conforme explicitado no artigo $5^{\circ}$ da Resolução CNE/CEB n. 02/2012:

2- Considera-se a noção gramsciana de estado ampliado (sociedade política com sociedade civil).

3- A esse respeito, Ciavatta e Ramos (2012) fazem um interessante debate evidenciando os projetos em disputa no processo de discussão das novas diretrizes curriculares para o ensino médio e para a educação profissional técnica de nível médio.
Art. $5^{\circ} 0$ ensino médio em todas as suas formas de oferta e organização, baseia-se em:

I - formação integral do estudante;

II - trabalho e pesquisa como princípios educativos e pedagógicos, respectivamente; [...]

$\S 1^{\circ} 0$ trabalho é conceituado na sua perspectiva ontológica de transformação da natureza, como realização inerente ao ser humano e como mediação no processo de produção da sua existência.

$\S 2^{\circ}$ A ciência é conceituada como o conjunto de conhecimentos sistematizados, produzidos socialmente ao longo da história, na busca da compreensão e transformação da natureza e da sociedade. $\S 3^{\circ}$ A tecnologia é conceituada como a transformação da ciência em força produtiva ou mediação do conhecimento científico e a produção, marcada, desde sua origem, pelas relações sociais que a levaram a ser produzida.

$\S 4^{\circ}$ A cultura é conceituada como o processo de produção de expressões materiais, símbolos, representações e significados que correspondem a valores éticos, políticos e estéticos que orientam as normas de conduta de uma sociedade.

Diante do exposto, cabe explicitar mais uma contradição. A aprovação pelo Conselho Nacional de Educação (CNE) e a homologação pelo ministro de DCNEM, que apontam na direção da formação integral dos sujeitos é, evidentemente, um avanço, mas a sua materialização não está garantida, inclusive porque o necessário financiamento não foi assegurado, pois o horizonte que se coloca para ampliar os investimentos em educação para 10\% do PIB é de 10 anos e isso ainda não está aprovado definitivamente. Enquanto isso, as DCNEPTNM, que vão em direção contrária, já contavam com amplo financiamento por meio do PRONATEC, ainda antes de terem sido homologadas. 
Finalmente, em meio a essas disputas e contradições, para que se avance na direção de materializar a concepção de formação humana integral, é fundamental compreender que a histórica dualidade estrutural na esfera educacional não é fruto da escola, mas da sociedade dual/cindida em que se vive, por imposição do modo de produção capitalista. Isso exige que a escola se estruture de forma dual no sentido de fortalecer o modo de produção do capital que se baseia na valorização diferenciada do trabalho intelectual e do trabalho manual. Portanto, romper essa dualidade estrutural da educação escolar completamente não depende apenas do sistema educacional, mas, antes, da transformação do modo de produção vigente.

Contudo, isso não significa que desde a educação deva-se esperar que ocorra primeiramente a superação do atual modo de produção para, somente depois, construir-se uma escola compatível com o novo o modo de produção. É preciso atuar em meio às contradições do modelo hegemônico vigente no sentido de produzir movimentos que contribuam para o rompimento da dualidade educacional, o que também contribuirá para a superação do sistema capital.

\section{Referências}

BRASIL. Ministério da Educação. Secretaria da Educação Profissional e Tecnológica. O PRONATEC como política estruturante da educação profissional brasileira. Disponível em: <http://www.sinasefe-sc.org.br/>. Acesso em: 30 jul. 2012.

FRIGOTTO, Gaudêncio; CIAVATTA, Maria; RAMOS, Marise. A gênese do decreto n. 5.154/2004: um debate no contexto controverso da democracia restrita. In: (Org.). Ensino médio integrado: concepção e contradições. São Paulo: Cortez, 2005a.

(Org.). Ensino médio integrado: concepção e contradições. São Paulo: Cortez, 2005b.

CIAVATTA, Maria. (Org.). A formação do cidadão produtivo: a cultura de mercado no ensino médio técnico. Brasilia: Instituto Nacional de Estudos e Pesquisas Educacionais Anísio Teixeira, 2006.

GRAMSCI, Antonio. Os intelectuais e a organização da cultura. 4. ed. Rio de Janeiro: Civilização Brasileira, 1982.

INSTITUTO BRASILEIRO DE GEOGRAFIA E ESTATÍSTICA. Pnad 2008: Mercado de trabalho avança, rendimento mantém-se em alta, e mais domicílios têm computador com acesso à internet. [S.I.: s.n.], 2009. Disponível em: <http://www.ibge.gov.br/home/ presidencia/noticias/noticia_visualiza.php?id_noticia=1455\&id_pagina>. Acesso em: 20 maio 2012.

KUENZER, Acácia. Ensino médio e profissional: as políticas do Estado neoliberal. São Paulo: Cortez, 1997.

A educação profissional nos anos 2000: a dimensão subordinada das políticas de inclusão. In: Educ. Soc., Campinas, SP, v. 27, n. 96 - Especial, p. 877-910, out. 2006. Disponível em: <http://www.cedes.unicamp.br>. Acesso em: 20 jan. 2008.

A formação de professores para o ensino médio: velhos problemas, novos desafios. In: Educ. Soc., Campinas, SP, v. 32, n. 116, p. 667-688, jul./set. 2011. Disponível em: <http://www.cedes.unicamp.br>. Acesso em: 12 dez. 2011.

0 ensino médio no plano nacional de educação 2011-2020: superando a década perdida? In: Educ. Soc., Campinas, SP, v. 31, n. 112, p. 851-873, jul./set. 2010. Disponível em: <http://www.cedes.unicamp.br>. Acesso em: 30 jan. 2011.

MACHADO, Lucília Regina de Souza. Diferenciais inovadores na formação de professores para a educação profissional. In: Revista Brasileira da Educação Profissional e Tecnológica, Brasília, v. 1, n. 1, jun. 2008.

Ensino médio e técnico com currículos integrados: propostas de ação didática para uma relação não fantasiosa. In: MOLL, Jaqueline e Colaboradores. (Org.). Educação profissional e tecnológica no Brasil contemporâneo: desafios, tensões e possibilidades. Porto Alegre, RS: Artmed Editora, 2009. 
MACHADO, Maria Margarida. Quando a obrigatoriedade afirma e nega o direito à educação. In: Revista Retratos da Escola, Brasília, v. 4, n. 7, p. 231-243, jul./dez. 2010. Disponível em: <http://www.esforce.org.br>. Acesso em: 2 jan. 2011.

MANACORDA, Mario Alighiero. Marx e a pedagogia moderna. Campinas, SP: Editora Alínea, 2007.

MARX, Karl. Instruções para os delegados do Conselho Central Provisório: as diferentes questões. Lisboa: Avante Edições, 1982a. Disponível em: <http://www.marxists.org/portugues/mar//1866/08/instrucoes.htm>. Acesso em: 20 maio 2012.

Crítica ao programa de Gotha. Lisboa: Avante Ediç̃es, 1982b. Disponível em: <http://www.marxists.org/portugues/ marx/1875/gotha/index.htm>. Acesso em: 20 maio 2012.

0 capital: crítica da economia política. São Paulo: Nova Cultural, 1996.

; ENGELS, Friederich. Manifesto do Partido Comunista. Lisboa: Avante Edições, 1997. Disponível em: <http://www. marxists.org/portugues/marx/1848/ManifestoDoPartidoComunista/index.htm>. Acesso em: 1 jun. 2012.

MOURA, Dante Henrique. Políticas públicas para a educação profissional técnica de nível médio nos anos 1990 e 2000: limites e possibilidades. In: OLIVEIRA, Ramon de. (Org.). Jovens, ensino médio e educação profissional: políticas públicas em debate. 1. ed. Campinas, SP: Papirus, 2012.

RAMOS, Marise. 0 projeto unitário de ensino médio sob os princípios do trabalho, da ciência e da cultura. In: FRIGOTTO, Gaudêncio; CIAVATTA, Maria. (Org.). Ensino Médio: ciência, cultura e trabalho. Braśilia: Ministério da Educação, 2004. p. 37-52.

SAVIANI, Dermeval. A nova lei da educação: LDB, limite, trajetória e perspectivas. 8. ed. São Paulo: Autores Associados, 2003a. 2003b. . 0 choque teórico da politecnia. In: Educação, Trabalho e Saúde. Rio de Janeiro: EPSJV/FIOCRUZ, v.1, p. 131-152,

Dante Henrique Moura é professor do Instituto Federal de Educação, Ciência e Tecnologia do Rio Grande do Norte/Programa de Pós-Graduação em Educação Profissional (PPGEP). Possui graduação em engenharia elétrica pela Universidade Federal do Rio Grande do Norte (1986) e doutorado em Educação pela Universidade Complutense de Madri (2003). 